\title{
Acquired non-malignant tracheoesophageal fistula secondary to esophagogastroduodenoscopy in a patient on mechanical ventilation
}

\author{
Shrinivas Kambali MD, Raed Alalawi MD
}

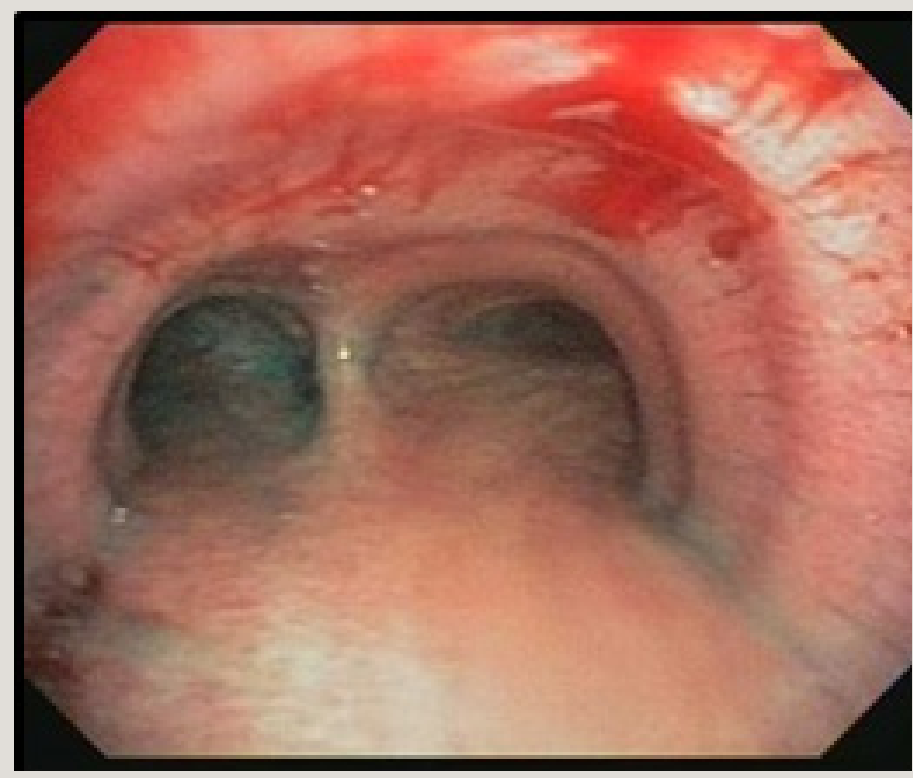

Figure 1 Normal trachea and carina.

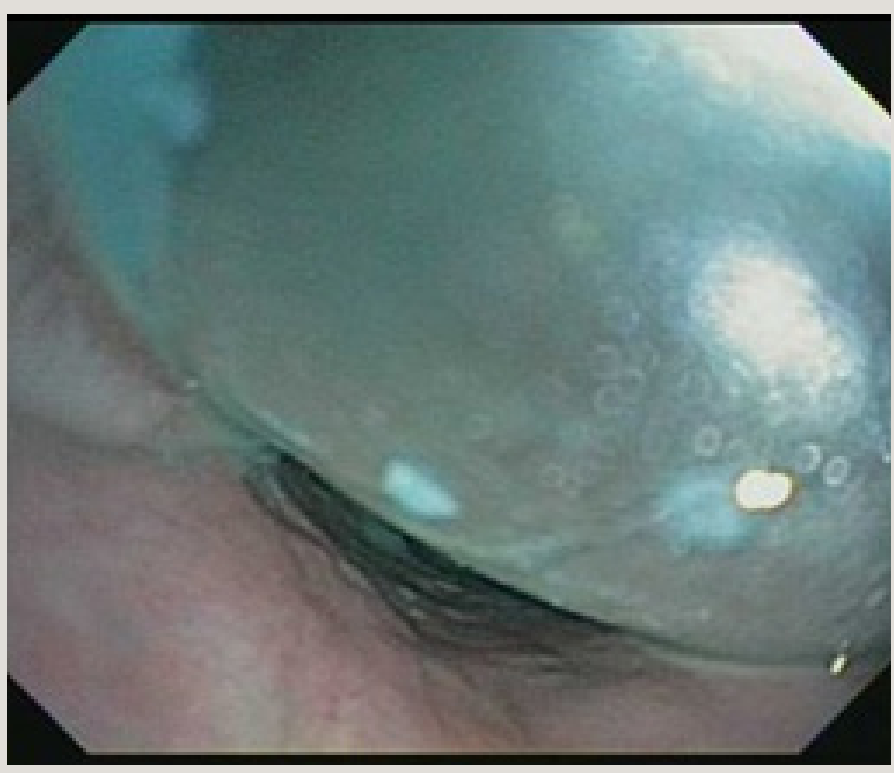

Figure 2 Tracheostomy cuff in esophagus.
A 73-year-old woman presented to the hospital with a non-ST segment elevation myocardial infarction and cardiomyopathy. She was intubated for mechanical ventilation, underwent a left heart catheterization, and had a stent placed in her LAD. Because of her cardiomyopathy, she did poorly during weaning trials. After discussions with the patient and family, she underwent an open tracheostomy and then a percutaneous gastrostomy (PEG) tube placement on consecutive days. The patient was disoriented the following day, had an elevated WBC, and started on broad spectrum antibiotics. She did not have any difficulty with mechanical ventilation at this time. There

Corresponding author: Shrinivas Kambali MD Contact Information: Shrinivas.kambali@ttuhsc.edu DOI: $10.12746 /$ swrccc 2013.0104.042 was no air leak or changes in peak airway pressures. There was no difficulty in passing the suction catheter through the tracheostomy tube. Clinical examination did not reveal any subcutaneous emphysema. A chest $x$-ray did not show any obvious pathology. She was tolerating her enteral feeding well. An abdominal ultrasound did not reveal any abnormality. She had a bronchoscopy through the tracheostomy which showed minimal secretions, a normal carina, and normal left and right bronchial trees (Figure1). The bronchoscope was then introduced through the mouth to evaluate the hypopharynx and cricopharynx. She had acquired a tracheoesophageal fistula (TEF) with an inflated tracheostomy cuff visible in the esophagus (Figure 2). Methylene blue was injected to the stomach through the PEG tube; this procedure was negative for a gastropulmonary fistula. 


\section{Discussion}

Acquired nonmalignant TEF in adults is very rare. ${ }^{1}$ The most common etiology is intubation with cuff-related tracheal injury. Our patient did not have any TEF before the EGD procedure during the PEG tube placement, and this is the probable cause of her fistula formation. Potential risk factors which could increase the risk for the TEF formation are her history of tracheostomy on the previous day, endotracheal intubation injury, increased cuff pressure in the endotracheal and the tracheostomy tube, her history of current steroid use, and diabetes. Some of these risk factors could cause TEF independently. The incidence of esophageal perforation during upper endoscopy is estimated at $0.03 \%$ and $0.11 \%$ during rigid endoscopy. ${ }^{2,3,4}$ The most common sites of iatrogenic esophageal perforation are at the normal anatomic narrowing in the hypopharynx or the cervical esophageal secondary to force exerted in attempting to pass the endoscope through the cricopharynx. ${ }^{2}$ It is most commonly associated with upper endoscopy interventions, such as esophageal dilation, high inflation pressure, previous laser or sclerotherapy, and history of esophageal cancer. latrogenic esophageal perforation during transesophageal echocardiography is a well-known cause of esophageal perforation and occurs with an incidence of $0.18 \%{ }^{2,5}$ In 1972 Hugh Harley reported 44 cases of TEF associated with tracheostomy with the estimated incidence to be 1 in $200 .^{6}$ Jugn et al. reported a case of TEF through esophageal diverticulum in a patient who had a prolonged tracheostomy tube. ${ }^{7}$ Other documented causes are tracheostomy, lung transplantation, thyroid resection, thoracic aneurysm repair, esophageal leiomyoma enucleation, mediastinoscopy, and cervical spine surgery. ${ }^{2,8,9,10,11}$

Common presentations include cough, recurrent pneumonia, increased secretions, and evidence of gastric aspiration into the trachea while on the ventilator. ${ }^{1}$ The cuff can completely occlude the fistula which might cause atypical presentations with less cough and fewer secretions. A high index of suspicion is very important in patients who have undergone procedures or have prolonged ventilator support with tracheostomy tubes. Bronchoscopy and esophagos- copy can help in the diagnosis of TEF. ${ }^{1}$

Immediate treatment includes placement of the cuff beyond the fistula to prevent more aspiration. Spontaneous closure is very rare, and surgical closure is usually indicated in most patients. ${ }^{1}$ Surgery should be postponed till the patient is weaned from the mechanical ventilation because high positive pressure ventilation can increase the chances of dehiscence, persistence of the fistula, and stenosis. ${ }^{1}$ Malignant TEF has a poor prognosis, and esophageal bypass and stenting are commonly used to treat malignant TEF. ${ }^{1}$

Author affiliation : Shrinivas Kambali is a pulmonary-critical care fellow at TTUHSC; Raed Alalawi is a pulmonary physician in the Department of internal Medicine, TTUHSC.

Received: 9/10/2013

Accepted: 9/14/2013

Reviewers: Kenneth Nugent MD

Published electronically: 10/16/2013

\section{References}

1. Reed MF, Mathisen DJ. Tracheoesophageal fistula. Chest Surg Clin N Am 2003 May; 13(2):271-89.

2. Wu JT, Mattox KL, Wall MJ. Esophageal perforations: new perspectives\&treatment paradigms. J Trauma 2007;63:1173-84 3. Gama AH, Waye JD. Complications and hazards of gastrointestinal endoscopy. World J Surg 1989;13:193-201

4. Silvis SE, Nebel O, Rogers G, et al. Results of the 1974

American Society for gastrointestinal endoscopy survey. JAMA 1976; 235:928-930.

5. Daniel WG, Erbel R, Kasper W, et al. Safety of transesophageal echocardiography. A multicenter survey of 10,419 examinations. Circulation 1991;83:817-821

6. Salmon F. Tracheostomy. Proc R Soc Med 1975 June; 68(6): 347-356.

7. Jung JH, Kim JS, Kim YK. Acquired Tracheoesophageal Fistula through Esophageal Diverticulum in Patient Who Had a Prolonged Tracheostomy Tube - A Case Report. Ann Rehabil Med 2011 June; 35(3): 436-440.

8. Williamson WA, Ellis FH. Esophageal perforation. In: Taylor MB, Gollan JL, Steer ML, Wolfe MM, eds. Gastrointestinal Emergencies. 2nd ed. Baltimore, MD: Williams \& Wilkins; 1997:31-35.

9. Gaudinez RF, English GM, Gebhard JS, et al. Esophageal perforations after anterior cervical surgery. J Spinal Disord 2000; 13:77-84.

10. Venuta F, Rendina EA, De Giacomo T, et al. Esophageal perforation after sequential double-lung transplantation. Chest 2000; 117:285-287.

11. Massard G, Wihlm JM. Early complications. Esophagopleural fistula. Chest Surg Clin North Am 1999; 9:617-631. 